\title{
Senka Hočevar Ciuha \\ INDIVIDUALNO MENTORSTVO, MOST MED POSAMEZNIKOM IN IZZIVOM UČEČE SE DRUŽBE
}

\section{POVZETEK}

Za slikovno predstavitev mentorja pogosto uporabljajo metaforično podobo mostu, kjer je mentor oseba, ki spodbuja drugo osebo, da vzpostavlja refleksijo o svojih izkušnjah, in deluje kot most, prek katerega se mentorirani povzpne $k$ novim oblikam znanja in zmožnosti. Osnovni mentorski model je odnos nekoga, ki je bolj izkušen, z nekom, ki je manj izkušen, z namenom, da manj izkušenemu pomaga, da se kot delujoča oseba integrira v okolje (kulturo), ki je lahko profesionalno, lokalno, umetniško ali kultura, povezana s specifičnimi področji. V pričujočem prispevku obravnavamo $v$ duhu časa pozne moderne in učeče se družbe tiste strategije individualnega mentoriranja, ki sovpadajo z zahtevami hitro spreminjajoče se družbene stvarnosti. Predstavljamo analizo podatkov iz. polstrukturiranega anketnega vprašalnika, ki je dal pregled nad množičnostjo in oblikami izvajanja individualnega mentorstva na nacionalni ravni v okviru operacije Razvoj in izvajanje novorazvitih programov za usposabljanje strokovnih delavcev v okviru ministrstva za znanost, izobraževanje, kulturo in šport ter Evropskih socialnih skladov, znotraj nje programa Usposabljanje mentorjev za učenje $v$ dvojicah in (e-)mentorstvo na Slovenski univerzi za tretje življenjsko obdobje. Na podlagi interpretacije podatkov opredeljujemo strategije individualnega mentorstva. V ospredje postavljamo tiste vidike, ki se na prvi pogled lahko zdijo tvegani (primer spodbujanja dihotomij), a prav zato poudarjajo pomen ustvarjalne živosti mentorskega odnosa in ga postavljajo bolj v svet umetnosti kot med obrtne veščine.

Ključne besede: individualno mentorstvo, študent, učeča se družba, mentorski odnos, učenje

\section{INDIVIDUAL MENTORING - THE BRIDGE BETWEEN THE INDIVIDUAL AND THE CHALLENGES OF THE LEARNING SOCIETY - ABSTRACT}

The mentor is often metaphorically represented as a bridge - he is the person who encourages others to reflect on their experiences and thus acts as the bridge, allowing the mentees to reach new forms of knowledge and abilities. The mentorship relationship is a relationship which a more experienced person has with a less experienced person in order to help him or her get integrated - as active participant - into his or hers environment (culture), professional, local, artistic or a specific domain of culture. In the spirit of late modernity and the learning society, we deal in the article with the strategies of individual mentoring that coincide with the requirements of the rapidly changing social reality. We present an analysis of the data obtained by means of a semi-structured questionnaire, reviewing a multiplicity of methods of individual mentoring at the national level, within the framework of the project The Development and Implementation of Newly Designed Programmes for Training of Professional Workers, under the auspices of the Ministry of Science, Education, Culture and Sport and the European Social Fund. Included in the project is a programme for training of mentors for learning in pairs and (e-)mentoring at the Slovenian Third Age University. Through an interpretation of the data we determine the strategies in individual mentoring. We highlight those aspects which, at the first glance, may appear risky (e.g. promoting dichotomies), thus emphasizing the importance of creative vitality in mentoring relationships, which raises mentoring into the realm of art rather than craftsmanship.

Keywords: individual mentoring, student, learning society, mentoring relationships, learning

UDK : 374.7

V pozni moderni je izobraževanje odraslih vse bolj individualizirano in inovacijsko, saj od posameznika zahteva, da razvije tisto sposobnost, ki mu omogoča, da skladno s procesi družbene preobrazbe pridobi mnogotere sposobnosti, veščine, znanja in vednost tako, da se posveti kontinuiranemu samostojnemu učenju. Habermas (1974) je v sedemdesetih letih 
zapisal, da je najbolj razširjen sodobni model učenja »neoseben tehnični model «, ki sloni na t. i. tehnični racionalnosti (technical mode of rationality), ki vzpostavlja kot pomembno posplošeno znanje $\mathrm{z}$ eksplicitnimi pravili in procedurami, kar velja tudi za izobraževalne pristope. Povsod naj bi bili jasno postavljeni cilji, ki so merljivi in preverljivi ter pripomorejo k uspešnosti v kompetitivni družbi. Gre za učenje, ki vodi k vnaprej natančno določenim ciljem. V sodobnosti takšen pristop ni več mogoč, saj živimo v hitro spreminjajočem se okolju, kjer ne moremo napovedati prihodnjih potreb. Ljudje potrebujejo tako učenje, ki poteka vzporedno z dejavnostjo (učenje in situ) in $\mathrm{z}$ drugimi vključenimi (sodelovalno učenje). Hutchins (1970) poudarja dva razloga za razvoj učeče se družbe: več prostega časa in hitrost sprememb. Znanje postaja last človeštva in ne posameznika. S tem sicer dobiva novo dimenzijo in se reducira na informacijo, ki jo mora posameznik kompleksno integrirati z učnim ciljem. Takšno izobraževanje je vse bolj individualizirano in inovacijsko. Pojem samostojno učenje implicira učenje skozi lastne napore, vendar tudi predpostavlja, da se odvija $\mathrm{v}$ povezavi $\mathrm{z}$ drugimi viri in ne $\mathrm{v}$ izolaciji. Odraslih več ne poučujemo, temveč jim ponujamo pomoč za razvijanje osebnih učnih načrtov. Zaradi mnogovrstnosti individualiziranih izobraževalnih potreb se vedno bolj razvijajo strategije mentorstva in svetovanja.

\section{MENTORSTVO KOT "PAS DE DEUX«}

V svetu plesne umetnosti so simbolni prepleti materializirani $\mathrm{v}$ telesnem gibu. Izraz $\mathrm{v}$ naslo$\mathrm{vu} »$ pas de deux« je vzet iz klasičnega baleta, kjer pomeni en korak dveh. V plesnih koreografijah partnerska plesalca izvajata predvsem skoke, kjer ob soplesalcu drugi plesalec izvaja skoke s pomočjo podpore. To daje vtis lebdenja na odru. Tako lahko s tem simbolnim prikazom individualnega mentorstva ponazorimo moč simbiotičnega in dialoškega odnosa.

Osrednji del razprave o individualnem mentorstvu oz. mentorstvu kot koraku dveh bo namenjen veščinam in metodam, potrebnim za uspešno mentorstvo. Značilnost mentorstva je diadni odnos. To prinaša tudi vprašanja zaupljivega odnosa; zaupljiv odnos je (lahko) prednost, lahko pa je vir težav ter celo zlorab in manipulacij. Pot mentoriranja je zato lahko poimenovana tudi umetnost, saj zahteva osebno zrelost, prilagodljivost, ki daje mentorirancu občutek osebne vrednosti, mu omogoča kontinuirano vizijo cilja, vmes pa v mnogih pomembnih sekvencah učnega odnosa uravnoteža učinkovanje tistih dejavnikov, ki bi lahko negativno vplivali na dosego cilja. Negativnih vplivov ni treba vedno odstraniti, temveč jih lahko uporabimo za vpogled ali kot potencial za refleksijo mentoriranca, mentorja ali odnosa med njima.

Sodobni kulturni kontekst (ki smo ga nakazali že v uvodu) zahteva od posameznika, da je prilagodljiv hitrim spremembam, da je inovativen/kreativen (refleksivna praksa), da je fleksibilen v svojem učenju in da hitro prilagaja svoje znanje glede na potrebe situacij ter da je zmožen delovati v skupinah (timsko delo, sodelovalno učenje, akcijsko raziskovanje). $\mathrm{Ob}$ vseh teh zahtevah po prilagodljivosti, hitrosti, prožnosti mora ohranjati psihično blagostanje in rezilientnost (odpornost proti stresu).

\section{USPOSABLJANJE MENTORJEV ZA UČENJE V DVOJICAH IN (E-)MENTORSTVO}

V okviru programa Usposabljanje mentorjev za učenje $\mathrm{v}$ dvojicah in (e-)mentorstvo smo si 
zastavili nalogo, da ob sodelovanju predavateljev Filozofske fakultete Univerze v Ljubljani in Pedagoške fakultete Univerze v Mariboru posredujemo strokovna znanja, ki bodo prek sodelovalnih institucij Ljudske univerze Ajdovščina, Ljudske univerze Velenje in Ljudske univerze Kranj v 120 urah usposabljanja širila vedenje in prakso o strategijah, evalvaciji in ne nazadnje tudi tehnološki podpori individualnemu mentorstvu. Prenesli bomo tudi primere dobre prakse gibanja »Znaš, nauči drugega « in dolgoletnih spoznanj prakse Univerze za tretje življenjsko obdobje v Ljubljani. V prvi fazi izvajanja projekta smo naredili prerez stanja, ki naj bi z analizo polstrukturiranih anketnih vprašalnikov dal pregled nad množičnostjo in oblikami izvajanja individualnega mentorstva.

\section{Analiza vprašalnika}

Prejeli smo 31 izpolnjenih vprašalnikov, vrnjenih po navadni pošti, faksu in elektronski pošti.

Med vsemi, ki smo jim poslali vprašalnike za izpolnitev ali nadaljnje prepošiljanje, je vprašalnike izpolnilo 14 moških (45 odstotkov) in 17 žensk (55 odstotkov).

Skoraj polovica anketiranih individualnih mentorjev (45 odstotkov) je starih med 60 in 69 let, polovica manj, 22,6 odstotka, je starih med 30 in 39 let, ena mentorica ima manj kot 29 let.
Dobra petina vprašanih (23 odstotkov) ima dokončano štiriletno srednjo šolo, 19 odstotkov jih ima dokončano višjo izobrazbo, največ, 58 odstotkov, pa jih je $\mathrm{z}$ visoko izobrazbo.

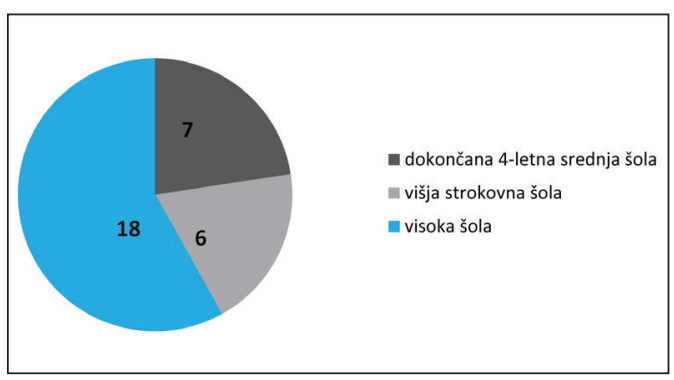

Nekateri izmed vprašanih mentorjev še niso mentorirali individualnih študentov, po štirje mentorji so imeli dva, tri in štiri študente, trije mentorji so imeli pet študentov, dva mentorja sta imela šest študentov, en mentor pa je individualno mentoriral osem študentov. Ker individualno mentorstvo še ni zelo znano, sklepamo, da je naslednje odgovore treba obravnavati s premislekom, saj nikjer ni bila podana definicija te prakse $\mathrm{v}$ nastajanju.

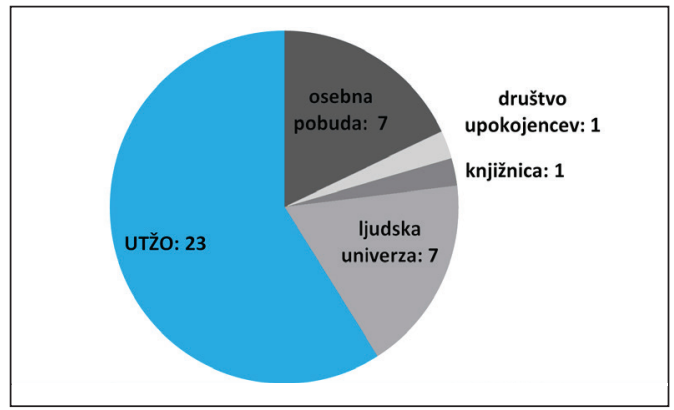

Največ individualnega mentorstva (74 odstotkov) se izvaja v okviru univerz za tretje življenjsko obdobje, kar je tudi razumljivo, saj je slovenska mreža NVO izobraževanja starejših prva, ki je uvedla ta koncept pri nas, in sicer pod imenom »Znaš, nauči drugega«. V okviru ljudskih univerz tako mentorstvo prakticira sedem mentorjev. Le sedem mentorjev oz. slaba četrtina vprašanih se je 
individualnega izobraževanja lotilo na osebno pobudo med prijatelji in znanci, medtem ko so mentorji preostalih organizacij, ki so vključene v prej omenjeno mrežo, potrebovali zunanjo spodbudo in animacijo.

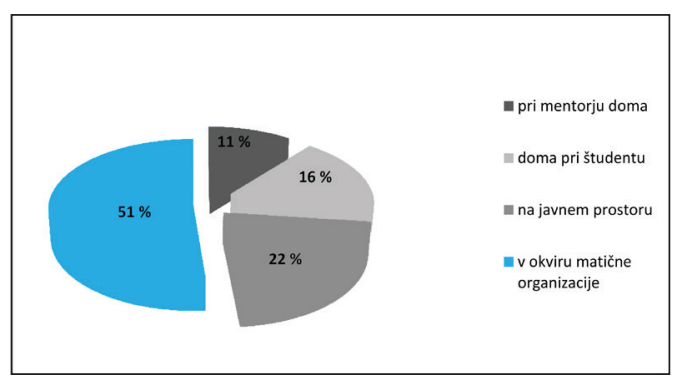

Mentor se s študentom v okviru individualnega izobraževanja v polovici primerov srečuje $\mathrm{v}$ prostorih matične organizacije, tj. ljudske univerze, društva upokojencev ali univerze za tretje življenjsko obdobje. Osem mentorjev se s svojimi študenti srečuje na javnih prostorih (v kavarnah, knjižnicah in različnih kulturnih centrih), dobra četrtina pa se jih srečuje na svojih domovih, ali pri mentorju ali pri študentu.

Individualni mentorji povečini delujejo na področju računalniškega izobraževanja (68 odstotkov), šest mentorjev (19 odstotkov) jih individualno poučuje tuje jezike, trije mentorji poučujejo vsebine s področja osebne rasti, po en mentor pa slikarstvo oz. keramiko, varno vožnjo in pisanje. Štirje mentorji so dali druge odgovore (planinstvo, zeliščarstvo, nordijska hoja).

Največ mentorjev se je za individualno mentorstvo odločilo zaradi mnenja, da so starejši vedoželjni (58 odstotkov vprašanih), polovica mentorjev rada prenaša svoje znanje na druge, 39 odstotkov pa jih rado dela z ljudmi. Trije vprašani menijo, da je to najbolj učinkovita oblika učenja, prav tako trije pa pravijo, da za njihovo temo ni učne skupine. Mnenje, da so starejši potrebni pomoči, je prisotno pri petih mentorjih, tretjina jih meni, da je to najboljši način za premagovanje začetnega strahu in odpora pred novim, četrtina pa jih meni, da jim oblika individualnega podajanja znanja olajša učenje.

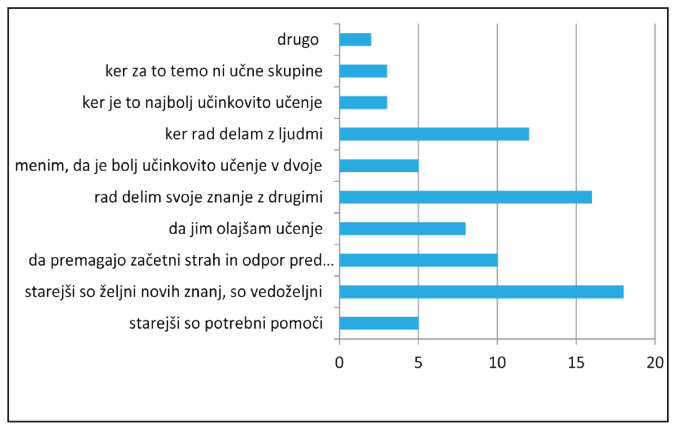

Največ mentorjev $\mathrm{v}$ okviru individualnega mentorstva pri izobraževanju uporablja pogovor in razlago, slaba polovica se tega loteva s pomočjo razlage napak, tretjina mentorjev pa mentorstvo starejši osebi izvaja s spremljanjem njenega napredovanja, svetovanjem o virih učenja in svetovanjem za premostitev težav pri učenju. Najmanj mentorjev skrbi za zagotavljanje učnih sredstev.

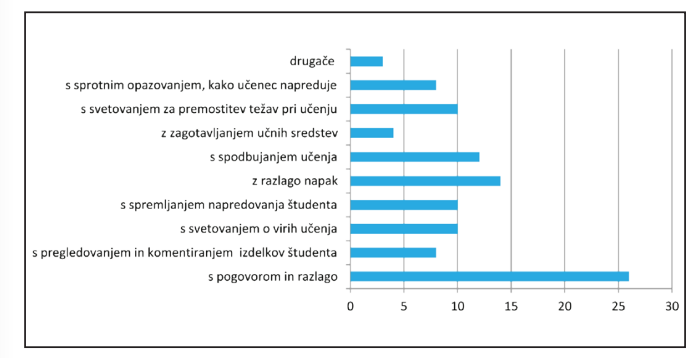

Polovica vprašanih mentorjev meni, da je največja ovira za izvajanje individualnega mentorstva $v$ tem, da ta praksa še ni v navadi. Tretjina jih ugotavlja, da so ovire materialne možnosti in pa dejstvo, da se individualno mentorstvo premalo ceni. Samo eden od mentorjev opaža, da je ovira nezadovoljivo predznanje študenta, manj pogosto navajajo tudi pomanjkanje motivacije študenta in omejene možnosti za posredno komunikacijo. 


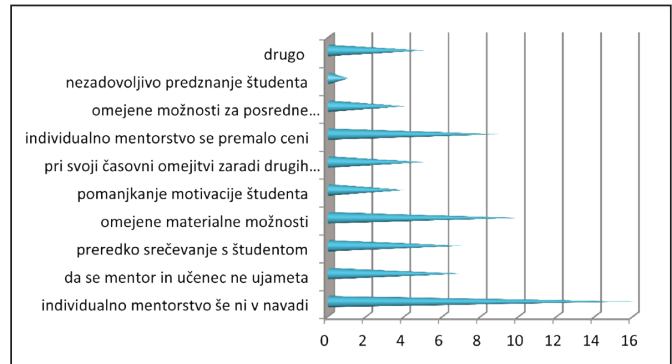

Velika večina mentorjev, ki so odgovarjali na vprašalnik, meni, da je individualno mentorstvo v prednosti pred učno skupino, saj je povsem prilagojeno posamezniku, prav tako se med mentorjem in študentom stkejo osebni odnosi in prijateljske vezi. Zgolj en mentor pravi, da se s takim izobraževanjem laže ohranja motivacija študenta, manj kot 15 odstotkov mentorjev pa ugotavlja, da se tako dosega večja samostojnost pri delu in zahtevnejše znanje, izobraževanje pa je tudi vsebinsko bolj razgibano.

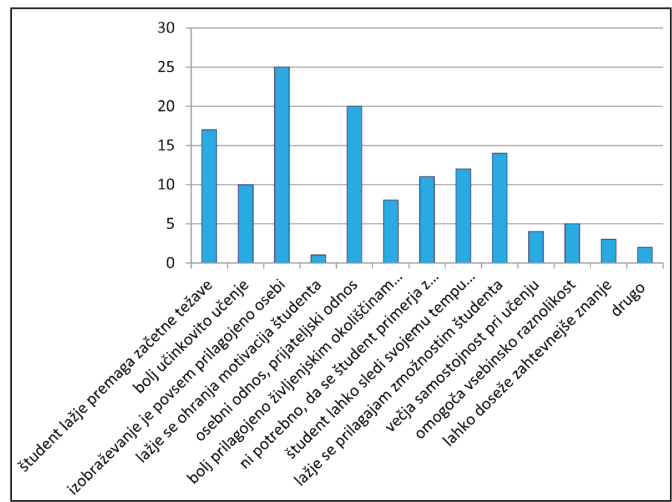

Po mnenju vprašanih mentor za individualno mentorstvo za svoje delo najbolj potrebuje veselje do ukvarjanja z ljudmi. Polovica mentorjev še ugotavlja, da mora biti mentor za individualno mentorstvo strpen do drugačnosti, znati mora poslušati, obvladovati mora medosebne odnose, predvsem pa mora imeti dovolj znanja s področja, ki ga mentorira. Prav tako mora biti mentor sposoben vživljanja v drugega, biti mora prilagodljiv za nepredvidljive situacije, nositi osebno odgovornost in drugo.

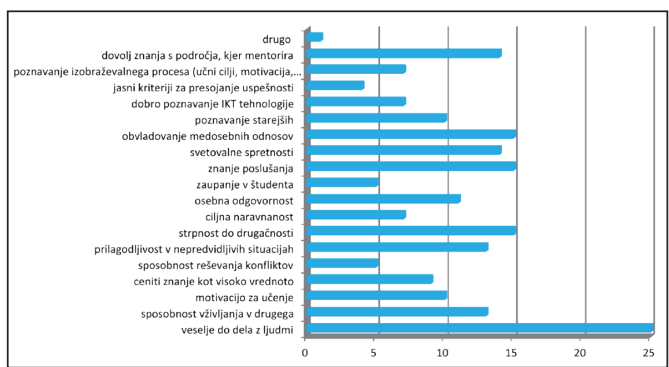

Prednosti e-mentorstva za starejše vidijo vprašani predvsem $\mathrm{v}$ tem, da lahko izobraževanje poteka $\mathrm{v}$ domačem okolju, s čimer se premagujejo težave pri fizični mobilnosti, prav tako je izobraževanje bolj prilagojeno posamezniku. Ovire za e-mentorstvo pa se skrivajo predvsem v negativnem mnenju, češ da je e-mentorstvo preveč brezosebno in ne daje možnosti neposrednih socialnih stikov.
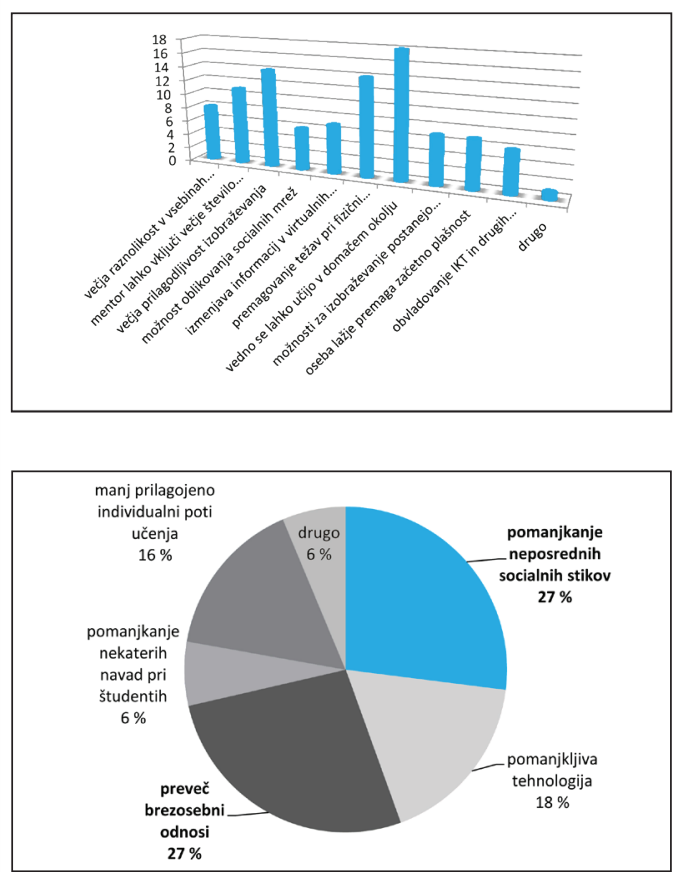

Kaj mentorji pričakujejo od usposabljanja za individualno mentorstvo? Predvsem 
spoznavanje značilnosti starejših odraslih. Prav tako pa določeno znanje s področja dinamike medosebnih odnosov, kako ravnati s starejšimi študenti, nekaj usposabljanja za svetovanje in psihološka znanja ter seveda tudi znanje s področja računalništva in e-mentorstva.

(Izdelava vprašalnika, analiza in interpretacija podatkov: dr. Ana Krajnc, Senka Hočevar Ciuha in Aleksandra Radojc)

\section{STRATEGIJE INDIVIDUALNEGA MENTORSTVA}

\section{Dajati samega sebe}

$\mathrm{Z}$ vprašanjem, kje se študent srečuje $\mathrm{z}$ mentorjem, smo se bolj kot o samem prostoru srečevanja spraševali o poglobljenosti mentorskega odnosa. Mentorji in študenti, ki so se v okviru gibanja »Znaš, nauči drugega « srečevali doma, so razvili učno uspešnejši, raznovrstnejši in prijateljski odnos. Iz analize podatkov pa razberemo, da se večina mentoriranja odvija $v$ okviru matične organizacije ali na javnem prostoru, ne pri mentorju ali mentorirancu doma, kar napeljuje na dejstvo, da je za zaupanje in povabilo v bolj intimno, domače okolje potreben daljši čas. Mentor v tej fazi nima vloge prijatelja, temveč vlogo učitelja, ki vodi do želenega učnega cilja.

Nemalokrat pa slišimo komentar bodisi mentorja bodisi študenta »želim si, da bi ga bolje poznal «. Na začetku mentorskega odnosa je distanca sprejemljiva. Avtoritativen odnos v prvi fazi je celo pogoj za potrebno začetno strukturo učnega procesa. S časom pa mora mentorski odnos izgubljati naravo avtoritativnosti, saj mora študent samostojno prepoznati mentorjeve nagibe in ustvarjeni ideal pretvoriti v življenjskega učitelja. Zato, ko mentor prepozna trenutek, ko je študent zrel za bolj poglobljen odnos, z njim deli tiste življenjske izkušnje, ki so pomembne za razvoj študenta $\mathrm{v}$ tem obdobju. V tretjem življenjskem obdobju je mentorski odnos obogaten z življenjskimi izkušnjami tako mentorja kot študenta in je poudarjena vzajemnost odnosa. Vloga mentorja se prepleta med obema in je enakovrednost odnosa dragocen prispevek k socialni mreži starejšega.

\section{Enkratnost odnosa}

Na vprašanje o prednostih individualnega izobraževanja z mentorjem je največ anketirancev (80,6 odstotka) odgovorilo, da je tako izobraževanje povsem prilagojeno posamezniku. Prilagojenost izobraževanja posamezniku predpostavlja ne le, da imamo zanj učni načrt, ki je skladen $\mathrm{z}$ njegovimi potrebami in željami, temveč da tudi kot mentor prepoznamo posebne darove študenta in jih zaobjamemo $\mathrm{v}$ celovitost mentorskega odnosa.

Odnosu daje pomen občutek njegove enkratnosti. Študent se v njem prepozna kot neponovljiva in enkratna osebnost, ki je lahko dodatno obogatena $\mathrm{z}$ želenimi lastnostmi mentorja. Občutenje enkratnosti je tako $\mathrm{v}$ podporo kot v izziv. Sam odnos postane posebno kulturno okolje, v katerem so spodbujeni nekateri vidiki osebnostne rasti. V varnem in enkratnem odnosu postanejo meje notranjega sveta prehodne in študent dobi posebne priložnosti, ki so mu v vsakodnevnem življenju teže prepoznavne. Značaj enkratnosti daje odnosu tudi mentorjeva sposobnost poslušanja. $\mathrm{S}$ poslušanjem mentor študentu daje možnost novega uvida, ki lahko študenta do cilja pripelje po novi poti.

\section{Pomen izziva}

Pri vprašanju, kako individualni mentor izvaja individualno mentorstvo, bomo v ospredje 
postavili dva najbolj pogosta odgovora, prvi je s pogovorom in razlago (83,9 odstotka) in drugi z razlago napak (45,2 odstotka). Sklepamo lahko, da je tako učenje refleksivno za študenta in mu omogoča, da ob podpori mentorja samostojno pride do končnih rešitev.

Tako kot na eni strani mentorjeva podpora krepi vezi mentorskega odnosa, tako na drugi strani izziv študentu daje avtonomnost. To avtonomnost lahko razumemo kot iskanje poti, kjer lastne notranje strukture pod vodstvom mentorja zaživijo v novem okolju. Triangularnost med izzivom, študentovo predstavo cilja in pričakovanji uravnoteža ustvarjeno kognitivno disonanco. Leon Festinger (1957), ki je prvi uporabil izraz »kognitivna disonanca«, trdi, da v človeku obstaja težnja, da prebrodi disonanco in jo uskladi s svojim notranjim sebstvom. To je tudi bistvo učenja. Delujemo zato, da prebrodimo razpoke. Po drugi strani pa je poučevanje prav odpiranje razpok. Mentor daje študentu v razmislek, izziv tudi moteče informacije na poti, dejstva, vpoglede, teorije in interpretacije, ki preizprašujejo študentov pogled na svet, hkrati pa mu nakazujejo smernice za prilagoditev novih struktur novim okoliščinam ter razrešitev kognitivne disonance.

\section{Mentorstvo je ena od najbolj značil- nih oblik andrago- ške prakse}

Argyris in Schön (1974, 1976) $\mathrm{v}$ teoriji dejanja opredelita učenje kot prepoznavanje in popravljanje napak. Teorijo dejanja delita na »teorijo v uporabi« (»theory in use «) in na »prisvojeno teorijo« (»espoused theory «). Teorija v uporabi je implicitna teorija, znotraj katere so posameznikove teorije, ki obvladujejo njegovo dejansko vedenje; gre za tako imenovane tihe strukture, ki vključujejo predvidevanja o sebi, drugih in okolju ter ustvarjajo mikrokozmos znanosti o vsakodnevnem življenju (Argyris in Schön, 1974: 30). Prisvojena teorija pa izhaja iz trdi- tve, da so besede in prepričanja, ki jih uporabimo, strategije, s katerimi prepričamo druge, kako mi delujemo.

Kadar se posledice uporabljenih strategij ujemajo z željami posameznikov, je teorija $\mathrm{v}$ uporabi potrjena. Potrjena je skladnost med namenom in rezultatom. Ko uporabljene strategije ne sovpadajo z željami posameznikov, pa Argyris in Schön (1976) vpeljeta dva nova pojma za prepoznavanje napak oz. učenje iz napak in učenje $\mathrm{z}$ refleksijo: enojna učna zanka (»single-loop learning «) in dvojna učna zanka (»double-loop learning«). Učenje $\mathrm{z}$ enojno učno zanko se zgodi, ko za dosego ciljev uporabimo že preverjene strategije. Poudarek pri prepoznavanju in odpravljanju napak je na tehnikah in njihovi učinkovitosti. Učenje z dvojno učno zanko vključuje preverjanje vlog in njihovih meja ter učnih sistemov, ki so podlaga dejanskih ciljev in novih strategij. Refleksija je pri učenju z dvojno učno zanko ključna.

Zato morajo biti naloge, ki jih mentor postavi študentu, po eni strani jasne in razvidne, po drugi strani pa so lahko tudi nerazumljive, saj mentor vzdržuje vizijo, ki jo mora študent še razviti. Nemalokrat je dobrodošlo, da ima študent do določene mere neurejeno učno področje. Pot do cilja ni vnaprej jasno določena, zahteva tudi sprotno prilagajanje in ubiranje novih učnih poti. Tak postopek je na prvi pogled paradoksen, a študentu omogoča posploševanje principov učenja, da širše uvidi pomen dejavnosti in ne zgolj posamičen izsek naloge. Skozi takšno učno interakcijo se $\mathrm{v}$ študentu ponotranjijo tudi mentorjeva merila.

\section{Pomen udeležbe v diskusiji}

Ker je $\mathrm{v}$ individualnem mentorstvu po pridobljenih podatkih najpogosteje uporabljena metoda izobraževanja pogovor in razlaga ter 
če izhajamo iz enakovrednosti mentorskega odnosa, lahko povzamemo, da dialog $\mathrm{v}$ individualnem mentorskem odnosu študentu omogoča iskanje novih osebnih in učnih poti, preobrazbo in spreminjanje stališč oz. vrednot znotraj osebnega referenčnega okvira.

Brookfield (1983) poudarja, da sodelovalno učenje (»college learning«) vključuje postavljanje novih okvirov razumevanja. Izhajajoč iz teorije transformacijskega učenja (Mezirow, 1991), se naši okviri razumevanja spremenijo, kadar pride do transformacije $\mathrm{v}$ naših verjetjih ali stališčih ali kadar pride do transformacije naše celotne perspektive. Transformacijsko učenje je proces, $v$ katerem spremenimo svoje samoumevne referenčne okvire (pomenske sheme, miselne navade), s tem pa postanemo bolj inkluzivni, odprti, čustveno sposobni spremembe in reflektivni ter lahko tako oblikujemo verjetja in mnenja, ki se bodo izkazala za bolj resnična ali pravična, da upravljajo dejanja. Skozi transformacijsko učenje smo osvobojeni nekritičnega sprejemanja verjetij in mnenj drugih.

V pogovoru damo študentu priložnost, da izrazi svoj problem in napredek. Primarni pomen razvojne diskusije (Mezirow, »discourse «) je, da pomaga učencu, da opredeli različne vidike, različne poti reševanja problema ali pojava. Diskusija je napor, da najdemo soglasje, da zgradimo novo razumevanje.

Takšna diskusija, če poudarimo, je učinkovita, če mentor upošteva pomen tveganja in raziskovanja novih poti učenja, ki jih študent sam ne bi preizkusil. Skozi diskusijo mentor študenta ne »inštruira«, temveč skozi razumevanje njegovih vprašanj in misli sprašuje po motivih in vzrokih.

Palmer (1998) meni, da učiti pomeni ustvariti prostor, v katerem se udejanja poslušanje. Takšen prostor spoštuje raznolikost pogledov, v njem posameznik bolj jasno sliši svoj lastni glas. Prav tako pa je pomembno, da posameznik izstopi iz svojega lastnega sveta in se prepozna $\mathrm{v}$ očeh drugega.

\section{Spodbujanje dihotomij}

Pomen spodbujanja dihotomij je v ustvarjanju večjega pritiska za njihovo razrešitev. Lahko bi tudi rekli, da mentor namensko poudarja kognitivno disonanco v študentu. Ob tem je v študentu spodbujen tudi notranji dialog. Skozi proces sproščanja pritiska $\mathrm{z}$ notranjim dialogom mentoriranec gradi temelj, na katerem potem oblikuje sinteze, ki spajajo nasprotujoče si konce. Mentor v študentu razvija dialektično in diskurzivno mišljenje. Pomembno je, da študent ob tem prepozna legitimnost nasprotne naravnanosti.

\section{SKLEPNA MISEL}

Konec sedemdesetih je Ana Krajnc opredelila mentorstvo kot eno najznačilnejših oblik andragoške prakse in kot »posebno obliko vodenja $\mathrm{k}$ določenemu vzgojnemu/učnemu smotru«, ki vključuje dolgotrajnejši proces medsebojnih stikov/povezanih učnih epizod med mentorjem in posameznikom (Krajnc, 1979: 213). Kasneje se ob različnih opredelitvah učenja pojavijo tudi nove opredelitve mentorstva, ki poudarjajo spodbujanje posameznika, da razvije refleksijo o svojem profesionalnem delu ali o drugih področjih življenja (prim. Zannini, 2005). Sodobni izzivi mentorstva so neločljivo povezani z nepredvidljivostjo vsakdana, vse večjimi zahtevami po raznolikih znanjih in trdni, a sočasno fleksibilni osebnostni strukturi, da lahko posameznikreživi v teh turbulentnih časih. Izzivi za mentorstvo se kažejo na področju novih oblik, npr. e-učenje, in praks, kakršna je supervizija. Izziv je tudi v vlogi mentorja, ki 
spremlja ljudi ob življenjskih prelomnicah. Naslednji izziv je vprašanje profesionalizacije mentorskega dela (npr. formalna specializacija za mentorsko delo) in usposabljanja za mentorsko delo (razvoj kompetenc in standardov). Glede na poudarjen diadni odnos in dialoškost ter učinkovitost takega učenja se kot izziv za prihodnost kaže vprašanje, kako vključevati t. i. mentorsko konverzacijo v različna okolja, kako naj »mentorska konverzacija« postane del vsakdanjega življenja in s tem del posameznikove refleksivne prakse.

Za pozno moderno je tudi značilno, da se vzajemno povečuje število življenjskih alternativ. Učeča se družba je tudi družba priložnosti, zato moramo rekonstruirati okvir znanja, da bomo razumeli na eni strani naravo strukturne krize, na drugi strani pa naše priložnosti (Wallerstein, 1999). Vse večja individualizacija ne pomeni osamitve in izločitve iz družbenih vezi, temveč iskanje raznolikih življenjskih priložnosti, ki so izraz individualne odgovornosti. Pot med prepoznavanjem priložnosti in udejanjanjem individualne odgovornosti je pot učenja, mentoriranja, ki je dokaz, da vsako potovanje pripelje $\mathrm{k}$ želenemu cilju.

\section{LITERATURA}

Argyris, C. (1974). Behind the front page. San Francisco: Jossey-Bass.

Argyris, C. (1976.) Increasing leadership effectiveness. New York: Wiley-Interscience.

Brookfield, S. D. (1983). Adult Learners, Adult Education and the Community. Milton Keynes: Open University Press.

Festinger, L. (1957). A theory of cognitive dissonance. Evanston: Row, Peterson.

Habermas, J. (1974). Theory and Practice. London: Heinemann.

Hutchins, R. M. (1970). The Learning Society. Harmondsworth: Penguin.
Krajnc, A. (1979). Metode izobraževanja odraslih. Ljubljana: Delavska enotnost.

Mezirow, J. (1991). Transformative Dimensions of Learning. San Francisco: Jossey-Bass.

Palmer, Parker. J. (1998). The Courage to Teach. Exploring the inner landscape of a teacher's life. San Francisco: Jossey-Bass.

Wallerstein, I. (1999). Utopistike ali izbira zgodovinskih možnosti 21. stoletja. Ljubljana: Založba/*cf.

Wallerstein, I. (2000). Kako odpreti družbene vede. Ljubljana: Založba/*cf.

Zannini, L. (2005). La tutorship nella formazione degli adulti. Milano: Guerini Scientifica. 